\title{
Incidencia del nitrógeno en la producción de biomasa y ácidos grasos de la microalga Chlorella vulgaris en un fotobiorreactor de panel plano a escala laboratorio
}

\author{
Grupo de investigación en Biotecnología \\ Línea de investigación: Biotecnología \\ Diego Rubio Fernández• María Camila Ángel•• Wendy Pimienta•••
}

Recibido Mayo 31 de 2012

Aceptado: Marzo 22 de 2013

\section{RESUMEN}

Chlorella vulgaris, es un alga verde fotosintética que puede alcanzar contenidos de lípidos superiores al $30 \%$ en su peso seco por lo que es considerada una fuente potencial de materias primas para la producción de lípidos del tipo omega tres y seis y biodiesel. El objetivo del presente trabajo fue el de establecer el perfil de ácidos grasos en condiciones ambientales desfavorables estudiando la influencia del nitrógeno como estrategia para aumentar la concentración ácidos grasos en la biomasa obtenida. La investigación fue realizada a escala laboratorio evaluando tres diferentes concentraciones $100 \%, 20 \%$ y $10 \%$ de la fuente de nitrógeno utilizada $\left(\mathrm{NaNO}_{3}\right)$ en el medio de cultivo Bold Basal (BBM). Para esta evaluación se construyó un sistema de producción de biomasa, un fotobiorreactor (FBR) de panel plano. La producción de ácidos grasos monoinsaturados disminuyó en los ensayos dos y tres respectivamente mientras que el nivel en el contenido de ácidos grasos saturados presentó resultados similares en los tres tratamientos, contrario a lo observado con los ácidos grasos polinsaturados (PUFAs).

La variación de la cantidad de biomasa obtenida en las condiciones de supresión de nitrógeno sugiere una posible alteración metabólica, primando la acumulación de sustancias de reserva como los lípidos, en detrimento de la división celular. Finalmente, fue posible analizar que para mantener un balance entre producción de biomasa y acumulación de lípidos, emplear una reducción del $80 \%$ de la fuente de nitrógeno del medio de cultivo Bold Basal (BBM) proporciona buenos resultados, debido a que puede generar concentraciones celulares del orden de los 30.000.000 Cel $/ \mathrm{mL}$ en tan sólo seis días de cultivo y aumentando la fracción lipídica de ácidos grasos saturados y polinsaturados.

Palabras Clave: Microalgas, Ácidos grasos, biomasa, Chlorella sp, ácido oleico.

\footnotetext{
- Docente Investigador Universidad de América. Grupo de Investigación Biotec-Fua. Departamento de Investigaciones, Oficina M09 Monteverde, Universidad de América Bogotá-Colombia. Correo electrónico: diego.rubio@profesores.uamerica.edu.co

•- Ingeniera Química Universidad de América Grupo de Investigación Biotec-Fua. Correo electrónico: mcangelcruz@gmail.com

... Ingeniera Química Universidad de América Grupo de Investigación Biotec-Fua. Correo electrónico: wendypimienta27@ gmail.com
} 


\section{ABSTRACT}

Chlorella vulgaris is a green microalgae with capacity to photosynthesize due to its high concentration of chlorophyll; it can reach lipid content above $30 \%$ in its dry weight. The goal of this study was found the fatty acid profile in unfavorable environmental conditions studying the influence of nitrogen as a strategy to increase the fatty acids. The research was carry out a laboratory scale evaluating three differents concentrations $100 \%, 20 \%$ and $10 \%$ nitrogen source used $\left(\mathrm{NaNO}_{3}\right)$ in the Bold Basal Medium (BBM). For this evaluation was built a biomass production system, a Flat Panel Photobioreactor. Monounsaturated fatty acids production decreased in the assays 2 and 3 . On the other hand the content of saturated fatty acids presented similar results in the three treatments.

The dry weight variation under nitrogen suppression conditions sugests a metabolic disorder prevailing accumulation of reserve substances (lipids and carbohydrates) in detriment of cell division. Finally it was possible to determine that to maintain a balance between biomass production and lipid accumulation an $80 \%$ reduction of nitrogen source in Bold Basal medium (BBM) should be used in order to obtain good results, in relation to cell concentrations, around 30.000 .000 cell/ $\mathrm{mL}$ in just six days of culture, and by increasing the lipid fraction of saturated and polyunsaturated fatty acids.

Key Words: Microalgae, Fatty acids, Biomass, Chlorella sp, Oleic acid

\section{INTRODUCCIÓN}

Los lípidos son importantes moléculas que son sintetizadas en la mayoría de las células vegetales, desde especies de alto porte hasta las microscópicas como las microalgas; se reconocen dos tipos de lípidos principales que son los polares, cuya función principal es ser parte de las membranas celulares y los no polares cuya función principal es ser moléculas de almacenamiento. Los lípidos no polares son definidos químicamente como triacilglicéridos, cumplen principalmente una función de almacenamiento de energía y son considerados altamente promisorios por su uso en la industria nutricional, farmacéutica y recientemente de biocombustibles (Molina et al, 1995; Meireles et al, 2003).
Se reconocen dos estados en los cultivos microalgales, de normalidad y de condiciones de estrés (Rodolfi et al, 2009); las condiciones de normalidad inducen a las células microalgales a usar la energía disponible en la división celular, mientras que las condiciones de estrés inducen a las células microalgales a acumular determinadas moléculas como proteínas, azucares y lípidos, es decir, se plantea que el estrés celular es un factor determinante que activa la acumulación de diferentes compuestos en las microalgas. El estrés a los cultivos se constituye en factor central del estudio de triacilgliceroles y en general lípidos en microalgas; ya que se ha encontrado una relación entre los agentes ambientales que modificados de cierta forma a los cultivos generan algún tipo de deficiencia fisiológica con la acumulación de lípidos apolares que juegan un importante papel en la adaptación de las microalgas a las condiciones del entorno (Rodolfi et al, 2009).

Actualmente se considera que uno de los escenarios de mayor aplicación de los lípidos microalgales se relaciona con la producción de biocombustibles como el biodiesel, el cual es una interesante alternativa a los combustibles fósiles siendo una fuente renovable y biodegradable que produce menos emisiones de gases con efecto invernadero. La viabilidad de estas aplicaciones depende en gran parte de las condiciones bajo las cuales son cultivadas las microalgas $y$ entre las que se encuentran temperatura, intensidad lumínica, nutrientes, suministro de $\mathrm{CO}_{2}$, $\mathrm{pH}$, entre otras. Por lo tanto, el estudio de diferentes estrategias de cultivo para aumentar la producción de ácidos grasos en microalgas, tales como los efectos causados por la manipulación de nutrientes como el $\mathrm{CO}_{2}$ y nitrógeno y los producidos por la intensidad y fotoperiodo de luz, se considera actualmente como un campo de investigación promisorio (Arias et al, 2013). Se ha demostrado que el nitrógeno es uno de los elementos más importantes en la moduclacion del crecimiento y productividad de lípidos en microalgas (Yeh et al, 2011) 
Rubio, Diego., et al: Incidencia del nitrógeno en la producción de biomasa...

LÍNEA DE INVESTIGACIÓN: BIOTECNOLOGÍA

Esta investigación tiene como propósito aumentar la acumulación de ácidos grasos en microalgas, mediante la manipulación de algunas de las condiciones de cultivo; en este caso, a partir de la variación en la concentración de nitrógeno en el medio de cultivo de la microalga Chlorella vulgaris cultivada en un fotobiorreactor de panel plano diseñado y construido a escala laboratorio.

\section{MATERIALES Y MÉTODOS}

\section{Cepa microalgal, condiciones de cultivo y medio cultivo}

La microalga empleada es Chlorella vulgaris la cual se cultivó inicialmente en un medio a base de un fertilizante agrícola foliar encontrado en el mercado a un bajo costo con el propósito de aumentar la producción de biomasa inicial a ser utilizada como inóculo en los ensayos de limitación de nitrógeno en el FBR.

Para la fase final de la experimentación donde se implementa la estrategia de limitación de nitrógeno en el FBR, se utilizó un segundo medio de cultivo, el medio Bold basal (BBM).

La composición estándar del medio de cultivo Bold Basal Medium (BBM) es (Watanabe, 2005): $0,25 \mathrm{~g} / \mathrm{L} \mathrm{NaNO}, 0,075 \mathrm{~g} / \mathrm{L} \mathrm{MgSO}{ }_{4} \cdot 7 \mathrm{H}_{2} \mathrm{O}$, $0,025 \mathrm{~g} / \mathrm{L} \mathrm{NaCl}, 0,075 \mathrm{~g} / \mathrm{L} \mathrm{K}_{2} \mathrm{HPO}_{4}, 0,175 \mathrm{~g} / \mathrm{L}$ $\mathrm{K}_{2} \mathrm{H}_{2} \mathrm{PO}_{4}, 0,025 \mathrm{~g} / \mathrm{L} \mathrm{CaCl}{ }_{2} \cdot 2 \mathrm{H}_{2} \mathrm{O}, 0,00882 \mathrm{~g} / \mathrm{L}$ $\mathrm{ZnSO}_{4} \cdot 7 \mathrm{H}_{2} \mathrm{O}, 0,00144 \mathrm{~g} / \mathrm{L} \mathrm{MnCl}_{2} \cdot 4 \mathrm{H}_{2} \mathrm{O}, 0,00071$ $\mathrm{g} / \mathrm{L} \mathrm{MoO}_{3}, 0,00157 \mathrm{~g} / \mathrm{L} \mathrm{CuSO}_{4} \cdot 5 \mathrm{H}_{2} \mathrm{O}, 0,00049$ $\mathrm{g} / \mathrm{L} \mathrm{Co}\left(\mathrm{NO}_{3}\right)_{2} \cdot 6 \mathrm{H}_{2} \mathrm{O}, 0,01142 \mathrm{~g} / \mathrm{L} \mathrm{H}_{3} \mathrm{BO}_{3}, 0,05$ $\mathrm{g} / \mathrm{L}$ EDTA, 0,031 g/L KOH,0,00498 $\mathrm{g} / \mathrm{L} \mathrm{FeSO}{ }_{4}$. $4 \mathrm{H}_{2} \mathrm{O}, 0,001 \mathrm{~mL} / \mathrm{L} \mathrm{H}_{2} \mathrm{SO}_{4}$.

La microalga se cultivó durante todo el estudio con agitación y suministro de $\mathrm{CO}_{2}$ por aire, impulsado por bombas el cual se esterilizó por un filtro compuesto por dos recipientes con cloro al 1 y $5 \% \mathrm{v} / \mathrm{v}$ y dos recipientes de agua; una temperatura de $24^{\circ} \mathrm{C}$ controlada y monitoreada por medio de un termostato; un fotoperiodo de 12 horas luz-oscuridad proporcionado por un tem- porizador manual, una fuente lumínica con longitud de onda de $700 \mathrm{~nm}$ (luz roja de 16 watts) instalada dentro de una incubadora de poliestireno expandido y un $\mathrm{pH}$ dentro de un rango de $6,3-7,5$.

\section{Crecimiento inicial de biomasa}

El inóculo se realizó en seis tubos de ensayo de $10 \mathrm{~mL}$, los cuales contenían $9 \mathrm{~mL}$ de medio de cultivo preparado con fertilizante foliar a los que se adicionó la microalga contenida en medio sólido. Después de cumplidos 15 días de crecimiento y adaptación de las microalgas al medio, se realizó el primer aumento de biomasa empleando seis recipientes de vidrio de $375 \mathrm{~mL}$, usando $5 \mathrm{~mL}$ de microalga cultivada en los tubos de ensayo y $25 \mathrm{~mL}$ de medio de cultivo, para un volumen de $30 \mathrm{~mL}$ en cada uno de los seis recipientes de vidrio.

La adición de medio de cultivo se ejecutó cada 8 días de manera periódica, debido a que se observó un crecimiento rápido de las microalgas, evidenciado por la oscura coloración verde y la disminución en el volumen contenido; esta adición inicia con $20 \mathrm{~mL}$ de medio y de ahí en adelante, se adiciona el doble, es decir, $40 \mathrm{~mL}$, $80 \mathrm{~mL}$ y $160 \mathrm{~mL}$ donde se alcanza un volumen de aproximadamente $300 \mathrm{~mL}$.Luego, se realiza un nuevo escalamiento, que se lleva a cabo en recipientes de $3 \mathrm{~L}$ llegando hasta un volumen de $1 \mathrm{~L}$ tomándose $500 \mathrm{~mL}$ de microalgas contenidas en los recipientes de $375 \mathrm{~mL}$ y $500 \mathrm{~mL}$ de medio de cultivo (Figura 1). Este volumen de microalga se mantiene hasta la etapa final de la investigación, mediante la adición periódica (cada 10 días) de medio de cultivo inicial con el fin de poseer cantidades considerables de biomasa para el paso al fotobiorreactor en el cual se evaluaran las tres concentraciones de nitrógeno. Para los escalamientos, al igual que en la inoculación, es necesario mantener un ambiente libre de agentes contaminantes, por lo que se emplea una mesa de vidrio limpiada con etanol al $70 \%$ y la esterilización de todos los recipientes y elementos mediante una autoclave durante 1 hora a $121^{\circ} \mathrm{C}$ y 15 psi. 
Para determinar las curvas de crecimiento tanto de los ensayos preliminares como de la evaluación del nitrógeno, se realizaron recuen- tos celulares directos en microscopio y cámara de neubauer cada 24 horas.

Figura 1. Proceso de Producción de biomasa microalgal. 1-A Inóculo en tubo de ensayo. 1-B Cultivo inicial en recipiente de $375 \mathrm{~mL}$. 1-C Cultivo en recipientes de $3 \mathrm{~L}$.

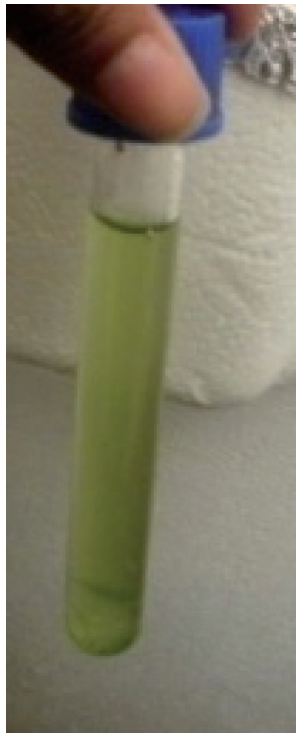

A

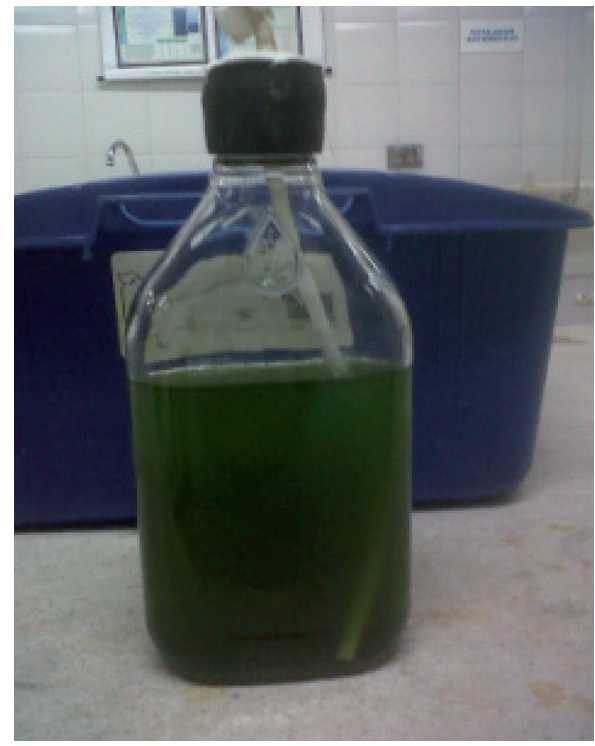

B

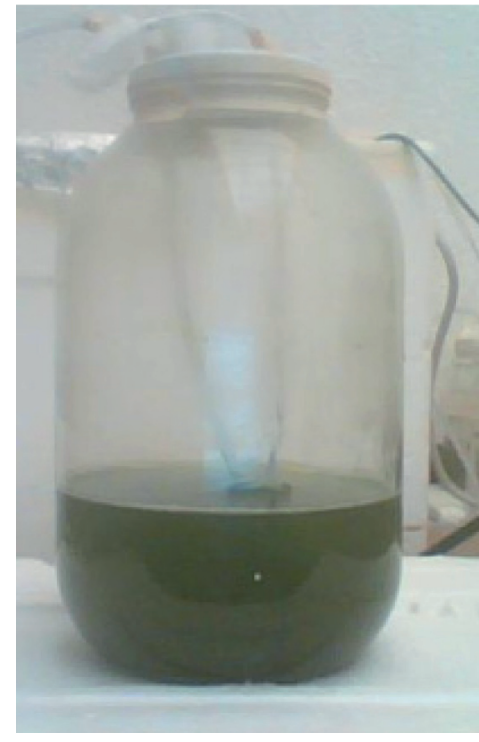

C

Fuente: Los autores

\section{Diseño y desarrollo del Fotobiorreactor (FBR)}

Se empleó un sistema cerrado de producción de biomasa para tener un mayor control en las condiciones de cultivo y disminuir la contaminación. Este sistema se operó por lotes o "batch" con el fin de facilitar la limpieza del mismo y no afectar la concentración de nitrógeno en el medio. El tipo de FBR seleccionado consiste en un fotobiorreactor de panel plano, considerado como un diseño especializado de alta eficiencia para la generación de biomasa microalgal (Reyna et al, 2010; Yen et al, 2010) construido en polimetilmetacrilato con un área de las láminas de $0,08 \mathrm{~m}^{2}$ y una distancia entre placa y placa de $0,04 \mathrm{~m}$ lo que da como resultado un volumen final de $0,0032 \mathrm{~m}^{3}$. Por otra parte, debido a que el sistema de desgasificación es simple, la eliminación de los gases producidos no es suficien- temente efectiva, por lo cual se deja un espacio de $0,0012 \mathrm{~m}^{3}$ entre la superficie del líquido y la parte superior del FBR, y a la vez se adapta un ducto desgasificador en la parte superior, evitando la presurización del equipo y la inhibición del crecimiento del cultivo a causa de la acumulación de oxígeno. Finalmente, la diferencia entre la capacidad del FBR y el espacio de 0.0012 $\mathrm{m}^{3}$ genera un volumen de trabajo de $0,002 \mathrm{~m}^{3}$.

El fotobiorreactor está equipado con un sistema de aireación proporcionado mediante un tubo aspersor de aire instalado en el interior del FBR. Además opera con una fuente de luz externa (luz roja de 16 Watts), una temperatura de $24^{\circ} \mathrm{C}$ y un fotoperiodo de 12 horas luz-oscuridad adaptados de la misma forma que en el crecimiento de la biomasa. 
LÍNEA DE INVESTIGACIÓN: BIOTECNOLOGÍA

Figura 2. Fotobiorreactor de Panel Plano empleado como sistema de producción de biomasa

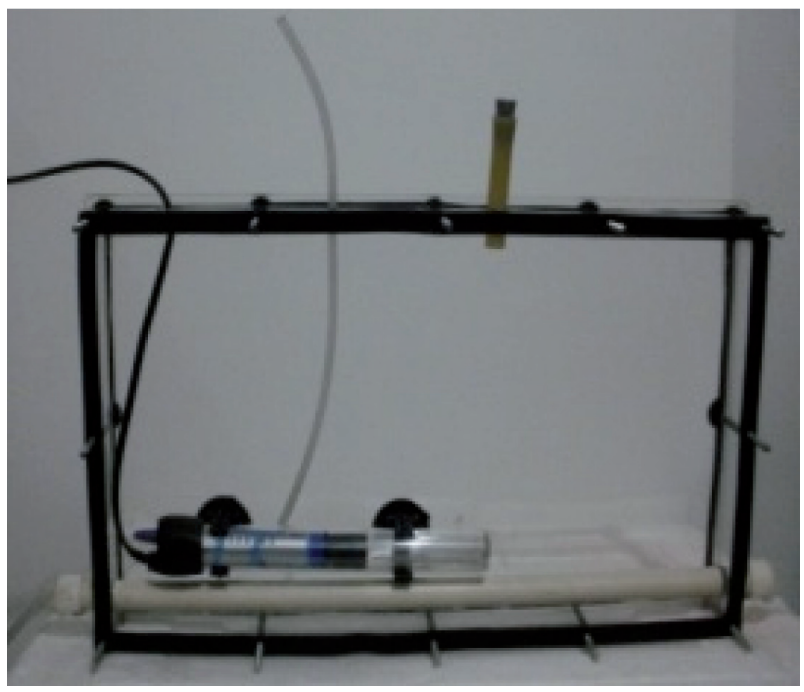

Fuente: Los autores

Para verificar el funcionamiento del fotobiorreactor y a la vez comparar los dos medios de cultivo utilizados, fertilizante foliar y Bold Basal medium (BBM), se realizan dos ensayos preliminares durante 12 días, empleando $900 \mathrm{~mL}$ de medio y $100 \mathrm{~mL}$ con microalga en los dos ensayos.

\section{Limitación de Nitrógeno en medio BBM}

Se establecieron tres diferentes concentraciones para comparar la producción de ácidos grasos en cada una de ellas, debido a que la literatura sugiere que la limitación de nitrógeno puede inducir a una mayor acumulación el contenido de lípidos de microalgas. Converti et al (2009) reportan reducciones de 1/2, 1/4, $1 / 5,1 / 8,1 / 10$ y $1 / 20$ de la principal fuente de nitrógeno del medio utilizado, de las cuales se seleccionan para realizar la investigación y el análisis de ácidos grasos, las concentraciones del $20 \%$ y $10 \%$ de $\mathrm{NaNO}_{3}$ en el BBM. Además, se decide elegir como tercera concentración, la cantidad de $\mathrm{NaNO}_{3}$ original en el medio Bold Basal (control), con el fin de establecer la dife- rencia en la producción de ácidos grasos entre un medio con altas cantidades de nitrógeno y los medios con escases de este nutriente.

\section{Siembra en Fotobiorreactor de Panel Plano y evaluación del efecto del nitrógeno}

La siembra en el FBR se realizó para cada una de las concentraciones a evaluar, es decir $20 \%$, $10 \%$ y concentración original del medio (control) haciendo tres réplicas por concentración que se dejan dentro del equipo por un periodo de 10 días. Cada uno de los procedimientos mencionados a continuación se realiza para todos los ensayos (las tres concentraciones) y sus respectivas réplicas. Se sedimentaron $1.5 \mathrm{~L}$ de la biomasa producida con anterioridad en fertilizante durante tres días con el fin de retirar este medio para lograr el paso a nuevo medio con limitación de nitrógeno. Finalmente, se obtiene un volumen de $250 \mathrm{~mL}$ de alga sedimentada que se resuspende en $1750 \mathrm{~mL}$ de BBM preparado a las diferentes concentraciones de nitrógeno establecidas. Tanto para el rendimiento volumétrico como para el perfil de ácidos grasos se empleó la biomasa producidas en la tercera réplica de cada ensayo.

\section{Deshidratación de la biomasa y productividad volumétrica}

En cada uno de los ensayos se producen $2 \mathrm{~L}$ de biomasa en el FBR, de los cuales, $400 \mathrm{~mL}$ se emplean para determinar el rendimiento volumétrico y los $1600 \mathrm{~mL}$ restantes se emplean como muestra para determinar el perfil de ácidos grasos de cada una de las concentraciones. Para deshidratar la biomasa se utiliza el método de centrifugación debido a que se describe como un método eficaz que permite recuperar entre el 80 y el $90 \%$ de las microalgas dentro de un corto tiempo (2-10 min) (Chen et al, 2010). Se maneja una velocidad angular de 4000 RPM por un tiempo de $10 \mathrm{~min}$. Esta técnica se emplea tanto para los ensayos de las tres diferentes concentraciones de nitrógeno como para los ensayos preliminares del FBR en don- 
Figura 3. Secuencia de proceso siembra en el Fotobiorreactor de Panel Plano para la evaluación del nitrógeno.

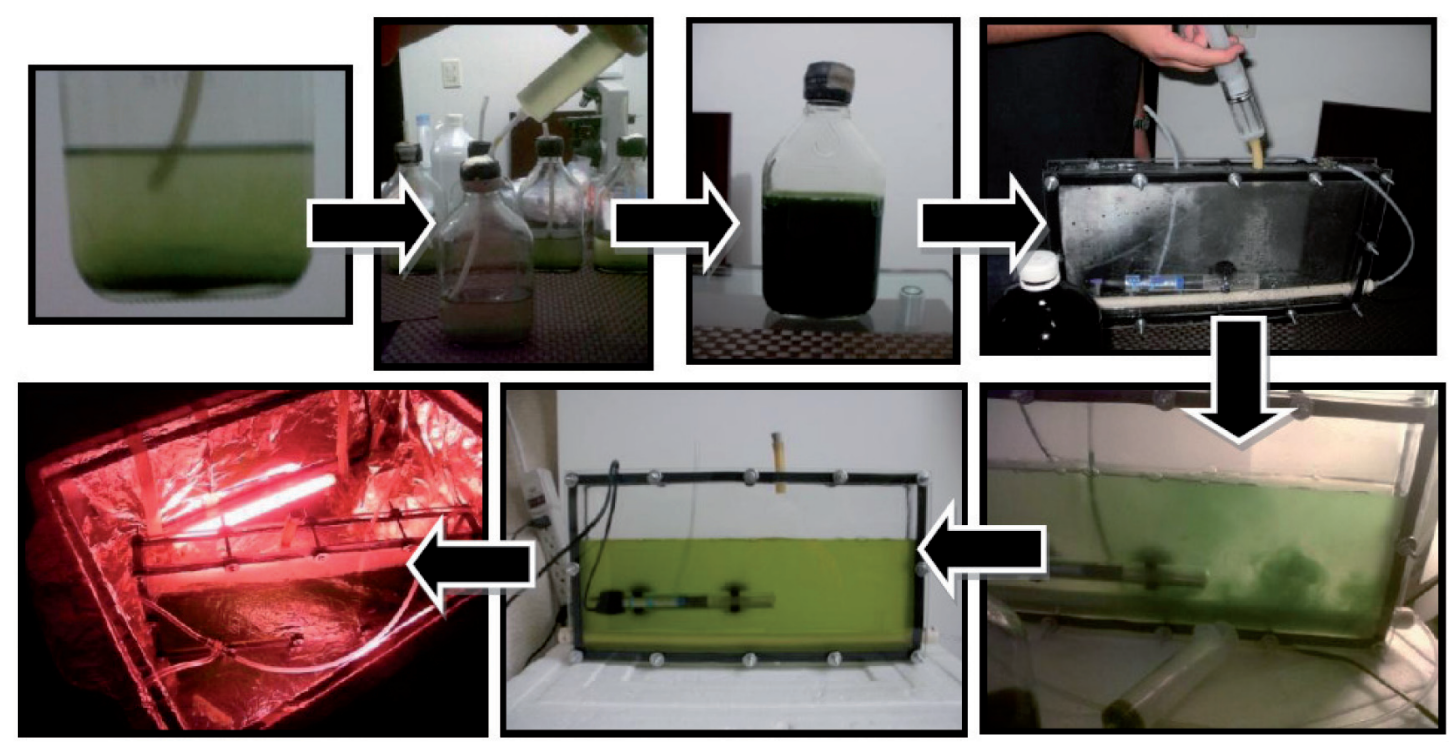

Fuente: los autores del proyecto

de se compara los dos medios empleados en este estudio. El volumen centrifugado resultante de los $400 \mathrm{~mL}$ de biomasa se vierte en un crisol para secarlo en un horno a $60^{\circ} \mathrm{C}$ durante tres horas y media y posteriormente pesar la biomasa seca en una balanza electrónica, con lo cual se determina el rendimiento o productividad volumétrica.

\section{Extracción de lípidos y perfil de ácidos grasos}

La biomasa obtenida de centrifugar los 1600 $\mathrm{mL}$ bajo las condiciones dos condiciones de limitación de nitrógeno (20\% y $10 \%)$ y el control se congela a $-80^{\circ} \mathrm{C}$ con el fin de liofilizarla para conservar la biomasa y facilitar el proceso de extracción de los ácidos grasos. La extracción de los ácidos grasos se efectúa por medio del método de Folch, en donde la muestra se extrae con una solución metanol-cloroformo en una proporción 2:1. La identificación y determinación de la composición de los ácidos grasos se lleva a cabo por cromatografía de gases, empleando un cromatógrafo de columna capilar GC 2014.

\section{Análisis estadístico}

La significación estadística de las variaciones observadas en las diferentes condiciones experimentales de limitación de nitrógeno fue establecida por medio de un análisis de varianza (ANOVA) empleando el estadístico de FisherSnedecor $(P<0,05)$.

\section{RESULTADOS Y DISCUSION}

\section{Sistema de Producción de Biomasa}

El sistema que se seleccionó para la producción de biomasa (FBR panel plano) presentó una distancia entre placa y placa de $4 \mathrm{~cm}$, puesto que rutas luminosas mayores a $10 \mathrm{~cm}$ no son recomendables para ningún tipo de FBR porque la distribución de la luz tiende a decrecer de forma importante en relación con el aumento en la densidad del cultivo (Contreras et al, 2008). Los FBRs de panel plano se caracterizan por su alta relación $S / N$, lo que permite una buena incidencia de la luz en el cultivo microalgal; por ello, las dimensiones seleccionadas para la 
Rubio, Diego., et al: Incidencia del nitrógeno en la producción de biomasa...

LÍNEA DE INVESTIGACIÓN: BIOTECNOLOGÍA

construcción del FBR deben asegurar que este importante parámetro de diseño sea alto. Al calcular la relación de superficie volumen se obtiene un valor de $25 \mathrm{~m}^{-1}$ valor considerado alto ya que esta relación se considera alta entre los
20 y $200 \mathrm{~m}^{-1}$ (Mata et al, 2010); lo cual indica que el FBR presenta un buen acceso a la luz, lo que permite que las microalgas realicen sin dificultades su proceso fotosintético, pero que tampoco se fotoinhiban.

Figura 4. Curvas de crecimiento de Chlorella vulgaris en el Fotobiorreactor de Panel Plano en medio tipo fertilizante foliar (foliagro) y en medio Bold Basal (BBM).

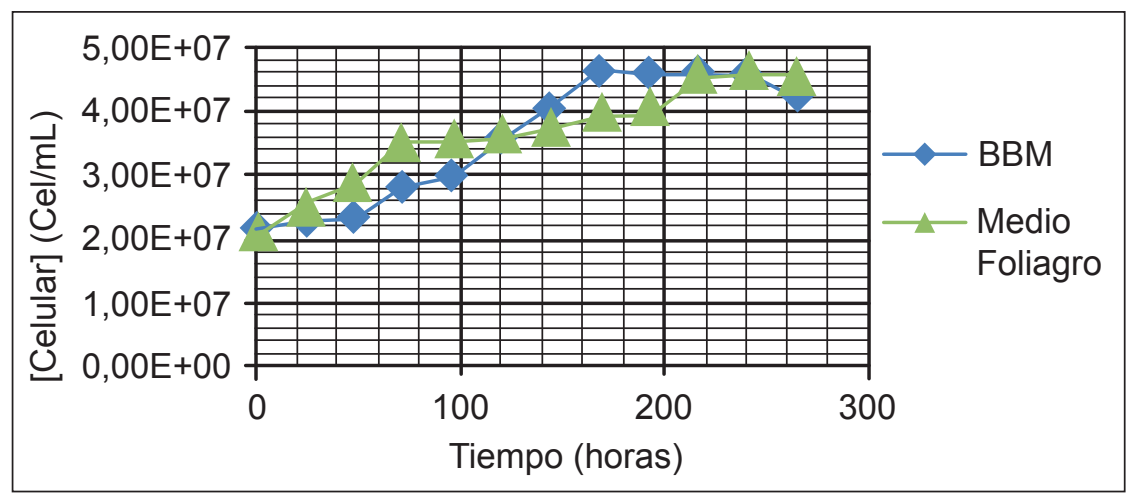

Fuente: Los autores

Los ensayos preliminares realizados en el FBR alcanzaron buenas tasas de división celular durante los 12 días de cultivo alcanzando concentraciones celulares de $46.400 .000 \mathrm{cel} / \mathrm{mL}$ en medio BBM Y 46.300.000cel $/ \mathrm{mL}$ en medio tipo fertilizante foliar permitiendo definir este medio como una nueva alternativa que proporción alta productividad y reducción en los costos de producción.

Estos ensayos también lograron productividades volumétricas del fotobiorreactor de 0,22 $\mathrm{g} / \mathrm{L}^{*} \mathrm{~d}$ en medio Foliagro y $0,2216 \mathrm{~g} / \mathrm{L}^{*} \mathrm{~d}$ en medio BBM, afirmando que es un sistema eficiente comparado con la productividad volumétrica teórica $\left(0,27 \mathrm{~g} / \mathrm{L}^{*} \mathrm{~d}\right)$ para FBR de panel plano según Wugu et al (2010).

\section{Evaluación del Nitrógeno en la producción de biomasa y lípidos}

La mayor tasa de densidad celular alcanzada por las microalgas se obtiene en el medio con concentración estándar de $\mathrm{NaNO}_{3}$ en $\mathrm{BBM}$ (33.300.000Cel $/ \mathrm{mL}$ ), que en comparación con el tratamiento 3 (1/5 de $\mathrm{NaNO}_{3}$ básico en BBM), es aproximadamente 1,3 veces mayor. Además se evidencia, que la limitación de nitrógeno en el medio produce un cese de la división celular, por lo tanto, la densidad de biomasa (células $/ \mathrm{mL}$ ) disminuye proporcionalmente en los tratamientos con limitación de nitrógeno (Fig. 5). Por otra parte, el primer tratamiento permite obtener una mayor concentración celular, pero en un periodo de tiempo más prolongado, y adicionalmente se aprecia que la mayor concentración celular alcanzada se obtiene después de los 10 días de cultivo (Fig. 5), la cual podría ser mayor según la tendencia de la curva; por otra parte, el segundo tratamiento, permite obtener una tasa de crecimiento de $30.600 .000 \mathrm{Cel} / \mathrm{mL}$ en tan sólo 6 días (Fig. 5)

El fotobiorreactor de panel plano construido tiene un alto rendimiento volumétrico de biomasa cuando la concentración de nitrógeno en el BBM es la estándar de este medio de cultivo. No obstante, este rendimiento se hace más bajo, cuando la concentración de nitrógeno en el medio se reduce, debido a la disminución de 
la concentración celular obtenida al final del cultivo causada por el estrés al cual se someten las microalgas por falta de uno de sus nutrientes más importantes, el nitrógeno (Fig. 5).

El análisis de varianza realizado para determinar los efectos de la concentración de nitrógeno en el medio de cultivo sobre la concentración de biomasa y por consiguiente sobre el contenido lipídico de las microalgas sugiere que debido a que $F_{c}$ es mayor que $F_{\alpha}$ se rechaza la hipótesis nula y se concluye que la concentración de nitrógeno tiene efectos significativos sobre la concentración celular o producción de biomasa (Tabla 1); este análisis se hizo con base a las curvas de crecimiento y no con respecto a los resultados del contenido de lípidos, debido a que se efectuó un solo análisis por cromatografía para cada uno de los ensayos establecidos, lo que genera pocas observaciones para realizar el ANOVA.

Figura 5. Curvas de crecimiento promedio de $C$. vulgaris para los tres ensayos experimentales en medio BBM. Ensayo $1100 \%$ de $\mathrm{NaNO}_{3}$. Ensayo 2 Concentración de $\mathrm{NaNO}_{3}$ disminuida al $20 \%$. Ensayo 3 Concentración de $\mathrm{NANO}_{3}$ disminuida al $10 \%$.

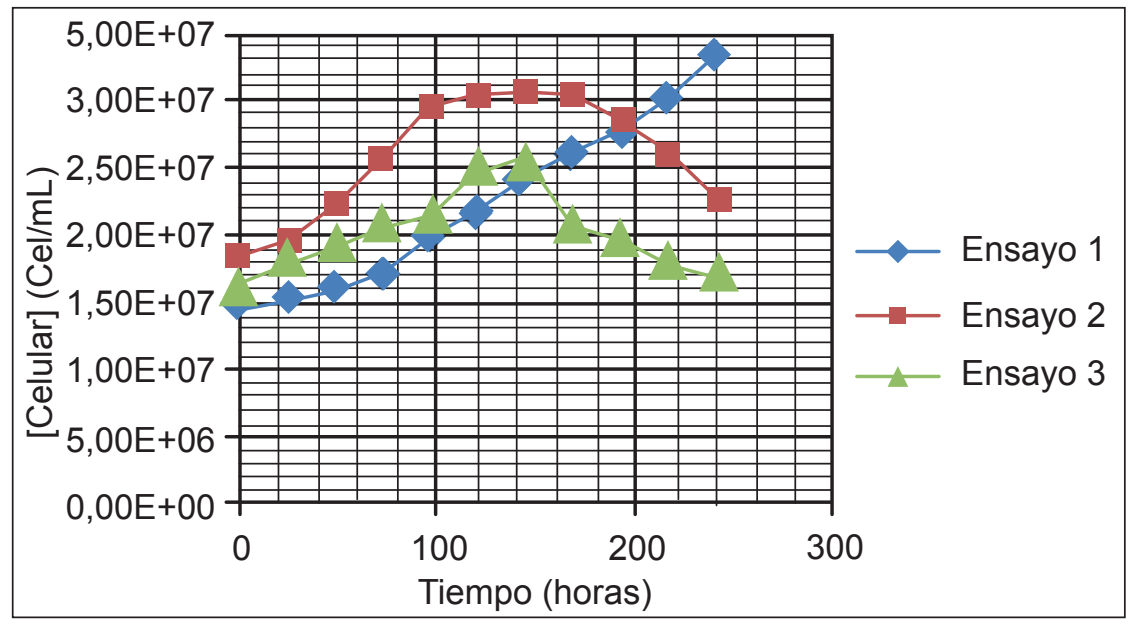

Fuente: Los autores

Tabla 1. Análisis de varianza para establecer diferencias en la producción de biomasa de acuerdo con las variaciones en la concentración de $\mathrm{NaNO}_{3}$

\begin{tabular}{|c|c|c|c|c|c|}
\hline Fuente de varianza & Suma de cuadrados & G.L & Cuadrados Medios & $\mathbf{F}_{\mathbf{c}}$ & $\mathbf{F}_{\alpha}$ \\
\hline$\left[\mathrm{NaNO}_{3}\right]$ & $5,10 \mathrm{E}+14$ & 2 & $2,54839 \mathrm{E}+14$ & 10,63 & 3,102 \\
\hline Error & $2,30 \mathrm{E}+15$ & 96 & $2,39735 \mathrm{E}+13$ & & \\
\hline Total & $2,81 \mathrm{E}+15$ & 98 & & & \\
\hline
\end{tabular}

Fuente: Los autores

La composición de ácidos grasos de los lípidos acumulados varía notablemente con la concentración de nitrógeno en el medio de cultivo (Fig. 6, Fig. 7), pues se observa un aumento de más del doble en los ácidos grasos polinsaturados (PUFAS) en los ensayos en condiciones de limitación de nitrógeno $50,13 \%$ para $1 / 5$ de
$\mathrm{NaNO}_{3}$ en $\mathrm{BBM}$ y $50,03 \%$ para $1 / 10$ de $\mathrm{NaNO}_{3}$ en BBM con respecto al control $20,52 \%$ para $\mathrm{NaNO}_{3}$ estándar en BBM. Además, se aprecia una reducción en el contenido de ácidos grasos monoinsaturados (MUFAS) en los ensayos 2 y $3(14,79 \%$ y $11,06 \%)$ de aproximadamente 3 y 4 veces respectivamente, en relación con el ensa- 
Rubio, Diego., et al: Incidencia del nitrógeno en la producción de biomasa...

LÍNEA DE INVESTIGACIÓN: BIOTECNOLOGÍA

yo $1(45,46 \%)$. No obstante, la cantidad de ácidos grasos saturados en proporción al total de ácidos grasos es similar para los tres ensayos realizados lo que puede indicar que la microalga Chlorella vulgaris en condiciones de crecimiento limitado por nitrógeno o estrés, tiende a acumular una mayor cantidad de ácidos grasos poliinsaturados (PUFAS) y ácidos grasos saturados (SFAS), disminuyendo la acumulación de ácidos grasos monosaturados (MUFAS) (Fig. 7).

Figura 6. Ácidos grasos obtenidos según los tres ensayos experimentales.

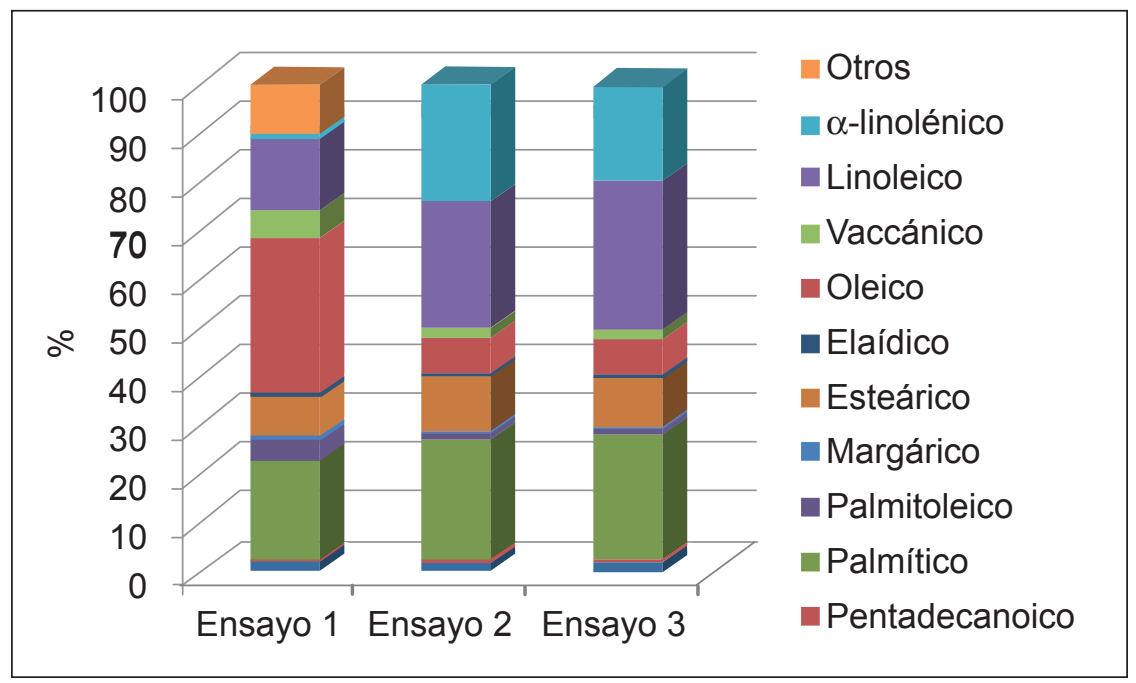

Fuente: Los autores

Figura 7. Tipos de ácidos grasos obtenidos en los ensayos experimentales según su grado de saturación

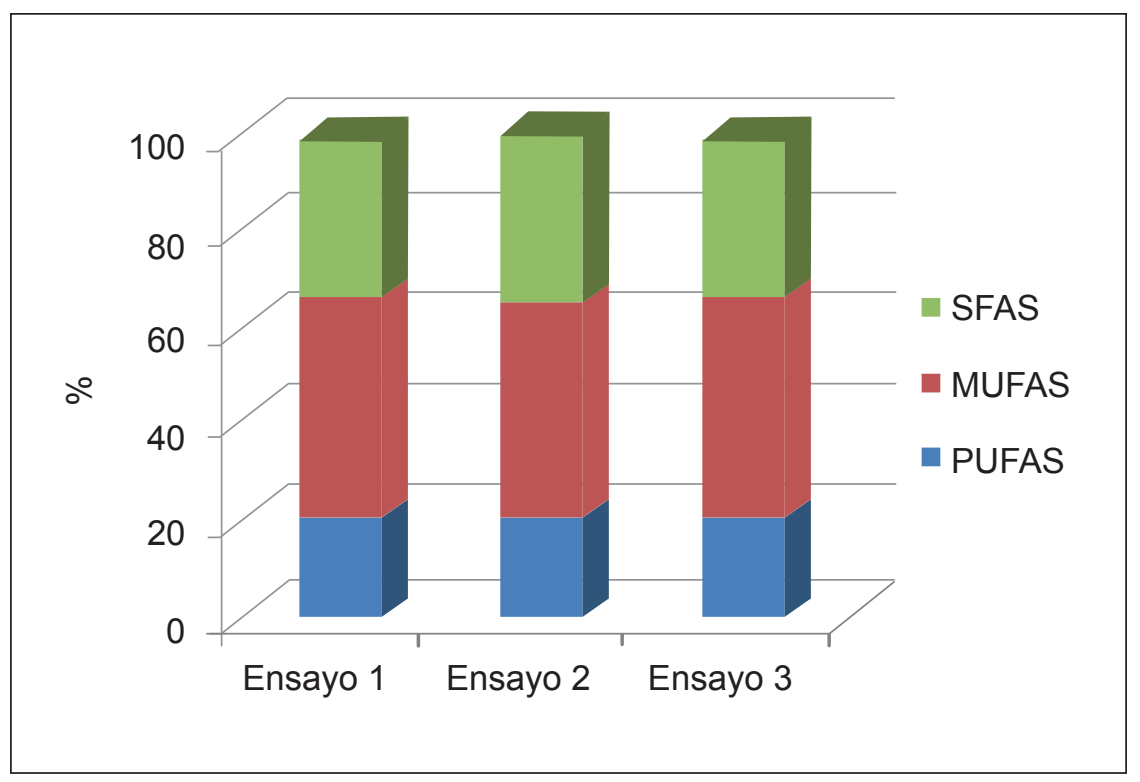

Fuente: Los autores 
De acuerdo con la aplicación a la cual se deseen enfocar los ácidos grasos producidos por las microalgas, más específicamente $C$. Vulgaris, se puede elegir el tratamiento más adecuado. Si el enfoque va dirigido a la alimentación humana, la industria farmacéutica o la aplicación en acuicultura, una buena condición de cultivo puede ser reducir la cantidad de nitrógeno en el medio, pues bajo estas condiciones se produce un aumento de los PUFAS. En la fabricación de pinturas, barnices, lacas y tintas, una buena opción es realizar un ensayo similar al 2, porque se genera una mayor cantidad de ácido linoleico y linolénico que poseen propiedades secantes. Para la producción de biodiesel los tres tratamientos evaluados presentan un buen perfil de ácidos grasos saturados, que son los más aptos para esta aplicación, aunque se plantea que es deseable tener una mayor concentración de acidos grasos saturados (Arias et al, 2013).

Mendoza et al (2007) plantean que el crecimiento en ambientes desfavorables o bajo situaciones de estrés, tales como la limitación de nitrógeno, conlleva a la acumulación de lípidos aunque con un detrimento de la división celular, que afecta la productividad lipídica, lo que es coherente con el presente estudio pues se observa que en los ensayos 2 y 3 la producción de biomasa se reduce, pero la fracción lipídica de ácidos grasos polinsaturados aumenta casi 2 veces en comparación con el primer tratamiento. Se sugiere que aunque los avances a nivel de producción de lípidos en microalgas han sido notables y significativos, la investigación en ese campo debe fortalecerse pues los costos generados en los procesos industriales aun son mayores que los generados en el caso de los combustibles fósiles (Arias et al, 2007)

\section{CONCLUSIÓN}

Se puede concluir que el sistema de producción de biomasa propuesto (FBR de panel plano) permite el buen desarrollo y productividad de los cultivos microalgales implementados, puesto que evita la sedimentación de las células gracias al sistema de aireación que contiene; además, el FBR de panel plano permitió una buena incidencia de la luz en el cultivo de las microalgas, debido a que su relación superficie-volumen fue alta $\left(25 \mathrm{~m}^{-1}\right)$ permitiendo a las células microalgales realizar sin problema el proceso de fotosíntesis evitando la fotohinibición.

La máxima concentración celular alcanzada en cada uno de los ensayos de evaluación de nitrógeno corresponde a $33.300 .000 \mathrm{Cel} / \mathrm{mL}$ para el primer tratamiento, $30.600 .000 \mathrm{Cel} / \mathrm{mL}$ y $25.500 .000 \mathrm{Cel} / \mathrm{mL}$ para el segundo y tercero en su fase exponencial; lo que evidencia el buen funcionamiento del FBR y a la vez permite corroborar que el crecimiento de la biomasa disminuye con concentraciones bajas de nitrógeno, debido a que este ejerce gran importancia como sustrato del medio utilizado (BBM).

La productividad volumétrica del sistema de producción de biomasa se ve afectada por las concentraciones de nitrógeno debido a que este reduce la división celular, dando como resultado productividades de $0,23,0,2125,0,185 \mathrm{~g} /$ día*L para los ensayos 1,2 y 3 respectivamente. Por tanto, la eficiencia del FBR que depende de la productividad, también disminuye de manera proporcional a la cantidad de nitrógeno en los tres tratamientos (ensayo 1: $85,19 \%$, ensayo 2 : $78,70 \%$ y ensayo $3: 68,52 \%)$.

Las condiciones ambientales desfavorables o de estrés (falta de nitrógeno en el medio) en Chlorella vulgaris ocasionan cambios en el contenido lipídico, donde prima la producción de ácidos grasos poliinsaturados y saturados. Por otra parte, la producción de ácidos grasos monoinsaturados disminuyó notablemente. Reducir la fuente de nitrato en el medio bold basal en un $80 \%$ mantiene un buen balance entre producción de biomasa y acumulación de lípidos, debido a que puede generar concentraciones celulares del orden de los $30.000 .000 \mathrm{Cel} / \mathrm{mL}$ en un menor tiempo de cultivo aumentando la fracción lipídica de ácidos grasos saturados y polinsaturados en comparación con el medio estándar. 
Rubio, Diego., et al: Incidencia del nitrógeno en la producción de biomasa...

LÍNEA DE INVESTIGACIÓN: BIOTECNOLOGÍA

\section{AGRADECIMIENTOS}

Los autores presentan un agradecimiento especial a la Dirección del Departamento de Investigación de la Universidad de América por el apoyo dado a este proyecto, a los ingenie- ros químicos Germán Castro, Elizabeth Torres y Juan Sandoval, docentes de la Universidad de América, a Oscar Contento, ingeniero químico, docente de la Universidad de La Salle y a la bacterióloga Luz Soraya Ángel por sus valiosos conceptos.

\section{REFERENCIAS BIBLIOGRÁFICAS}

Amaro, H. M., Guedes, C., Malcata, X. (2011). Advances and perspectives in using microalgae to produce biodiesel. Applied Energy Reviews. 88, 9, 3402-3410.

Arias, M., Martínez, A., Cañizares, R. (2013). Producción de Biodiesel a partir de microalgas: Parámetros del cultivo que afectan la producción de lípidos. Acta Biológica Colombiana 18, 1, $43-68$.

Contreras, C., Peña, J.M., Flores, L., Cañizares, R.O. (2003). Avances en el diseño conceptual de fotobiorreactores para el cultivo de microalgas. Interciencia 28, 8, 452 $-462$.

Converti, A., Casazza, A., Ortiz, E., Perego, P., Del Borghi, M. (2009). Effect of temperature and nitrogen concentration on the growth and lipid content of Nannochloropsis oculata and Chlorella vulgaris for biodiesel production. Chemical Engineering and Processing. 48, 6, 1147 - 1153.

Chica, C \& Parra, M. (2011). Obtención de Ácidos Grasos a partir de Biomasa Producida de Microalgas Chlorella a Escala Laboratorio., Trabajo de grado para optar al título de ingeniero químico. Bogotá, Universidad de América. Facultad de ingeniería. Departamento de ingeniería química. Bogotá D.C., 2011.

DISEÑO ESTADÍSTICO DE EXPERIMENTOS. Medellín Colombia: Universidad de Antioquia $2^{\circ}$ ed. 284p.

Mata, T., Martins, A., Caetano, N. (2010). Microalgae for biodiesel production and other applications: A review. Renewable and Sustainable Energy Reviews. 14, 1, 226- 238.

Meireles, L., Guedes, C., Malcata, X. (2003). Lipid Class of Pavlova luteri: Eicosapentanoic and Docosahexanoic Acids. Journal of Agriculture and Food Chemistry 51, 2237 2241.

Mendoza H., Molina C., De la Jara, A., Nordström, I., Freijanes, K., Carmona, L. (2008). Variación cuantitativa y cualitativa en ácidos grasos de Crypthecodinium cohnii en condiciones de supresión de nitrógeno. Grasas y Aceites. 59, 1, 27-32.
Molina, E., Sánchez, J., García, F., Robles, A., Giménez, A., Alonso, D. (1995). The Production of polyunsaturated fatty acids by microalgae : from strain selection to product purification. Process Biochemistry 30,8, 711-719.

Reina, R., Urbina, E., Hernandez, J., Thalasso, F., Cañizares, R. (2010). Hydrodinamic and mass trasnfer characterization of a flat - panel airlift photobioreactor with high light path.

Rodolfi, L., Chini, G., Bassi, N., Padivani, G., Biondi, N., Bonini, G. (2009). Microalgae for oil: stain selection, induction of lipid synthesis and outdoor mass cultivation in a low cost photobioreator. Biotechnology and Bioengineering 102, 1, 100-112.

Ugwu, U., Aoyagi, H., Uchiyama, H. (2008). Photobioreactors for mass cultivation of algae. Bioresource Technology $99,10,4026-4032$.

Wang, B., Lan, C., Horsman, M. (2012). Closed photobioreactors for production of microalgal biomasses. Biotechnology Advances 30, 4, 904-912. 
Yeh, K., y Chang, J. (2011). Nitrogen starvation strategies and photobioreactor design for enhancing lipid production of a newly isolated microalga Chlorella vulgaris
ESP-31: Implications for biofuels. Biotechnology Journal. 6 , 11, 1360- 1365.

Yen, C., Ling, K., Aisyah, R., Jong, D., \& Shu, C. (Enero,
2010). Cultivation, Photobioreactor Design and Harvesting of Microalgae for biodiesel Production.En: Bioresours Technology, 102, 1, 71-79. 